\title{
Pulsed Discharge Plasma for Pollution Control
}

\author{
Douyan Wang, Takao Namihira and Hidenori Akiyama \\ Kumamoto University \\ Japan
}

\section{Nonthermal Plasma for Air Pollution Control}

Air pollution caused by emission of a pollutant produced by a variety of sources must be substantially reduced as mandated by recent national legislations and international agreements. In recent years, several techniques have been used to remove pollutants from air, with various degrees of success. Nonthermal plasmas, in which the mean energy of electrons is substantially higher than that of the ions and the neutrals, offer a major advantage in reducing the energy requirements to remove the pollutants [1], [2]. The application of a short-duration pulsed power to a gaseous gap at an atmospheric pressure results in the production of nonthermal plasma.

Acid rain is partly produced by emissions of nitrogen oxides such as nitric oxide (NO) and nitrogen dioxide $\left(\mathrm{NO}_{2}\right)$ originating from fossil fuels burning in thermal power stations, motor vehicles, and other industrial processes such as steel production and chemical plants [3]-[8]. Nonthermal plasmas for removal of $\mathrm{NO}_{x}$ have been produced using an electron beam [9], [10], a dielectric barrier discharge [6], [11], and a pulsed corona discharge [8], [12][24] at various energy effectiveness. Nevertheless, energy loss occurs in each plasma processing system which cannot be neglected. For an electron beam system, it has been reported that only $26 \%$ of the input energy can be transferred to the plasma due to losses in the vacuum interface [25]. In a dielectric barrier discharge system, the input energy is largely consumed by the dielectric barrier and gas heating and cooling. Consequently, only $20 \%$ of the primary energy is transmitted into the plasma [26]. In a pulsed discharge, the input energy is mainly consumed in the pulse forming circuit, and the impedance mismatching between the generator and discharge electrode gap results in further energy loss. Approximately $30 \%$ of primary energy can be transmitted into the plasma [27]. In order to improve the energy efficiency of plasma processing system, the effect of the pulse duration on NO removal concentration was studied. The results showed the pulse duration of the applied voltage has a strong influence on the energy efficiency of the removal of pollutants [28], [29], shorter pulse duration is required to reach cost effective NO removal. Consequently, a detailed understanding of the development of streamer discharge using very short duration pulses is important for practical applications. Here it should be noted that $\mathrm{NO}_{2}$ can be converted to ammonium nitrate $\left(\mathrm{NH}_{4} \mathrm{NO}_{3}\right)$ by adding ammonia $\left(\mathrm{NH}_{3}\right)$ into the treatment gas, and $\mathrm{NH}_{4} \mathrm{NO}_{3}$ can be used to make fertilizer. Therefore, the major discussion is focused on removal of NO. The mechanism of NO removal is resulted from the plasma enhanced chemical reactions. The energy input into the discharge resulted in a 
larger number of collisions between electrons and the neutrals and produce the radicals such as $\mathrm{O}$ and $\mathrm{N}$ according to [30],

$$
\begin{aligned}
& \mathrm{e}+\mathrm{O}_{2} \rightarrow \mathrm{e}+\mathrm{O}+\mathrm{O} \\
& \mathrm{e}+\mathrm{N}_{2} \rightarrow \mathrm{e}+\mathrm{N}+\mathrm{N}
\end{aligned}
$$

as well as other reactions [31], which then remove NO via the following reactions [32]:

$$
\mathrm{O}+\mathrm{NO}+\mathrm{M} \rightarrow \mathrm{NO}_{2}+\mathrm{M}
$$

where $\mathrm{M}$ is a third body, which can be said $\mathrm{N}_{2}$ or $\mathrm{O}_{2}$. The reaction rate of $\mathrm{K}_{1}=6.9 \times 10^{-32} \mathrm{~cm}^{6} / \mathrm{s}$ [33] and

$$
\mathrm{N}+\mathrm{NO} \rightarrow \mathrm{N}_{2}+\mathrm{O}
$$

with a reaction rate of $K_{2}=5.9 \times 10^{-11} \mathrm{~cm}^{3} / \mathrm{s}[34]$.

\section{Observation of Pulsed Streamer Discharge and the Generation of Nano- seconds Pulsed Streamer Discharge}

\subsection{Methods and procedure}

The most effective condition of streamer discharges might be obtained from investigating the streamer propagation across the electrodes gap, the electrode impedance, and gas temperature of the discharges. Under this purpose, the emission from pulsed streamer discharges in coaxial electrodes geometry at $0.1 \mathrm{MPa}$ of air pressure was observed with the intensified charge-coupled display (ICCD) camera having a high-speed gate, a streak camera, and a spectrometer depending on the desired measurement.

The process of the streamer propagation can be obtained by taking framing and streak images with the camera system. Fig. 1 shows a schematic diagram of the experimental apparatus used to observe the positive and negative pulsed streamer discharges. A threestaged Blumlein line generator with a pulse duration of $100 \mathrm{~ns}$ was used as a pulsed power geneator [35]. The generator was charged either at positive or negative voltages by a dc high voltage source. A coaxial cylindrical reactor was utilized as a discharge electrode to observe pulsed steamer discharges. For each test, a positive or negative polarity voltage from the generator was applied to the central rod electrode.

The electrode impedance can be calculated from the applied voltage and discharge current through the electrode gap waveforms.

When an electrical discharge is initiated from the electrode, a large amount of excited species can be generated by electron impact processes. These active species contribute to the plasma-enhanced chemical reactions which can lead to decomposition of pollutant gases and ozone generation. Measurement of gas temperature is one of the important factors to understand the plasma reaction process, because it is an important parameter in gas reactions and is expected to be higher than the room temperature in the active region of streamers [36]. Measurement of the band spectra of second positive system of nitrogen 
molecule is one of the methods to examine the rotational temperatures of the $\mathrm{C}^{3} \Pi_{\mathrm{u}}$ and $\mathrm{B}^{3} \Pi_{\mathrm{g}}$ states by optical emission spectroscopy. Thus, the rotational temperature, which is assumed to be close to the gas temperature, can be determined by fitting the calculated spectrum with that measured experimentally [37].

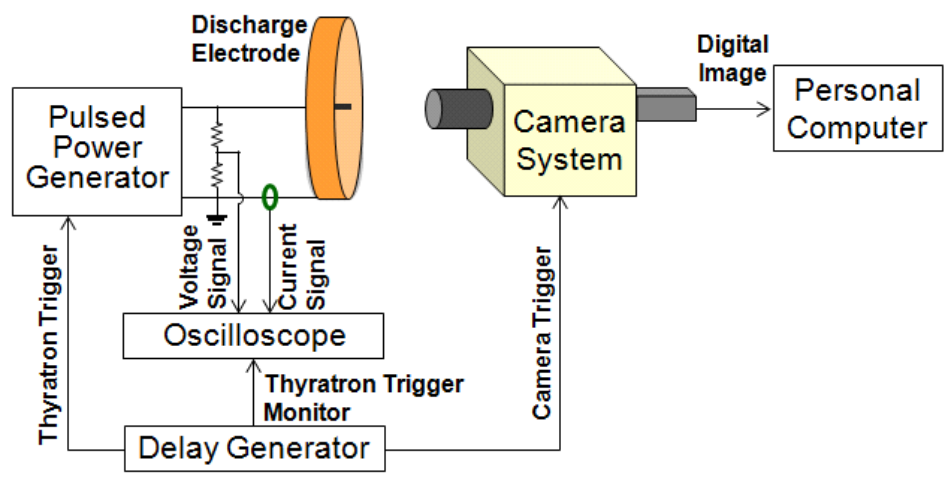

Fig. 1. Schematic diagram of the experimental apparatus used to observe the positive and negative pulsed streamer discharges. A rod made of stainless steel, $0.5 \mathrm{~mm}$ in diameter and $10 \mathrm{~mm}$ in length, was placed concentrically in a copper cylinder, $76 \mathrm{~mm}$ in diameter.

\subsection{Observation of general pulsed streamer discharge (Pulse duration of $100 \mathrm{~ns}$ with $25 \mathrm{~ns}$ rise and fall time)}

In a rod-to-cylinder coaxial electrode, the positive streamer discharge propagate straight in the radial direction from the coaxial electrode because the interactions between the electric fields near the neighboring streamer heads are the same at somewhere in the coaxial electrode geometry. The streamer heads are associated with a higher density of ionization due to the high electric field therein, and subsequently enhanced recombination, which is followed by increased light emission [35] (Fig.2, Fig.3). In positive pulsed streamer discharge, the emission at the vicinity of the rod electrode is observed 10-15ns after pulsed voltage application. The streamer heads were generated in the vicinity of the central electrode and then propagated toward the ground cylinder electrode. After full development of the streamer heads between the electrodes, the discharge phase transformed to a glow-like discharge with a large flow of current in the plasma channel produced by the streamer propagation. Finally, the glow-like discharge finished at the end of the applied pulsed voltage [35], [38] (Fig.3, Fig.4(a)). Therefore, two stages of the discharge can be clearly defined during the pulsed discharge. The first one is the 'streamer discharge', which means the phase of streamer heads propagation between electrodes. The other is the 'glowlike discharge' that follows the streamer discharge. Here it should be mentioned that in some publications, the track of the streamer head which propagates from the central rod electrode to the outer cylinder electrode is called as 'primary streamer', and the subsequent streamer head that started from the central electrode at $30 \sim 35$ ns (Fig.3, Fig.4(a)) and disappeared at the middle of the electrodes gap is called a 'secondary streamer'. In negative pulsed streamer discharge, the negative streamer head initiates in the vicinity of the central rod electrode and then propagates toward the cylinder wall electrode. After fully development of the streamer head across the electrode gap (time at the peak applied 
voltage), the discharge mode changed from a streamer to a glow-like discharge with a large discharge current, same as the positive one. It should be mentioned that discharge emission recorded near the surface of the rod electrode after the negative stramer head left the central rod is due to the surrounding photoionization and then the heat of the rod electrode surface. The propagation velocity of the streamer heads at certain time, $v_{\text {streamer }}$, can be given by

$$
v_{\text {streamer }}=\frac{\Delta L}{\Delta t}
$$

where $\Delta L$ and $\Delta t$ are the developed distance and time progress for its propagation from the streak images (Fig.4), respectively. The velocity of positive streamer is the same at certain applied voltage for different charging voltages, and the velocity increases with increasing applied voltage to the rod electrode. This may be due to the applied voltage to the rod electrode having a strong influence on the motion of the streamer head since there is a higher conductivity plasma channel between the rod and streamer head. The velocity of a negative streamer is approximately half that of positive streamers and also increases by increasing the absolute value of the applied voltage to the rod electrode. The propagation velocity of the streamer heads was $0.1 \sim 1.9 \mathrm{~mm} / \mathrm{ns}$ for a positive peak applied voltage of 15 $\sim 60 \mathrm{kV}$ of and $0.1 \sim 1.2 \mathrm{~mm} / \mathrm{ns}$ for a negative peak applied voltage $-28 \sim-93 \mathrm{kV}$, respectively. The electric field for streamer onset was constant at $15 \mathrm{kV}$ for all different applied voltages in positive streamers. Likewise, the applied voltage at streamer onset was $25 \mathrm{kV}$ for negative streamers. The electric field on the surface of the rod electrode before discharge initiation, $E_{0}$, were 12 and $20 \mathrm{MV} / \mathrm{m}$, respectively. $E_{0}$ is given by

$$
E_{0}=\frac{\left|V_{\text {applied }}\right|}{r \ln \frac{r_{2}}{r_{1}}}
$$

where $\left|V_{\text {applied }}\right|, r, r_{1}$, and $r_{2}$ are the absolute value of the applied voltage to the rod electrode, the distance from the center of the rod electrode, the radius of the rod electrode, and the inner radius of the cylinder electrode, respectively[35], [38].

The electrode impedance calculated from the applied voltage and discharge current through the electrode gap waveforms was about $13 \mathrm{k} \Omega$ in the streamer discharge phase and then dropped to $2 \mathrm{k} \Omega$ during glow-like discharge (Fig. 6(b)). Generally, impedance match between a power generator and a reactor is an important factor to improve higher energy transfer efficiency of the plasma processing system. This dramatic change of the electrode gap impedance during the discharge propagation makes it difficult to impedance match between the power generator and reactor.

Time dependence of the gas temperature around the central rod in a coaxial electrode geometry during a $100 \mathrm{~ns}$ pulsed discharge is shown in Fig. 7. The gas temperature remained about $300 \mathrm{~K}$ in the streamer discharge phase, and subsequently increased by about $150 \mathrm{~K}$ during the glow-like discharge. The temperature rise indicates thermal loss during the plasma reaction process that would lower gas treatment efficiency. 
From those points of view, it is clear that a large energy loss occurred in the glow-like discharge phase. Therefore, to improve energy efficiency of a pulsed discharge, a system should be developed for an ideal discharge which ends before it shifts to the glow-like phase. This can be achieved by designing a pulsed power generator with short pulse duration.

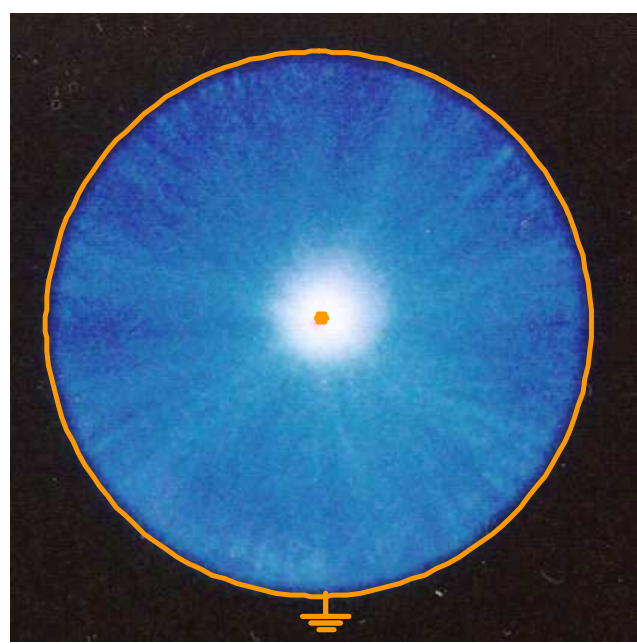

Fig. 2. Typical still image of a single positive pulsed streamer discharge taken from the axial direction in a coaxial electrode.

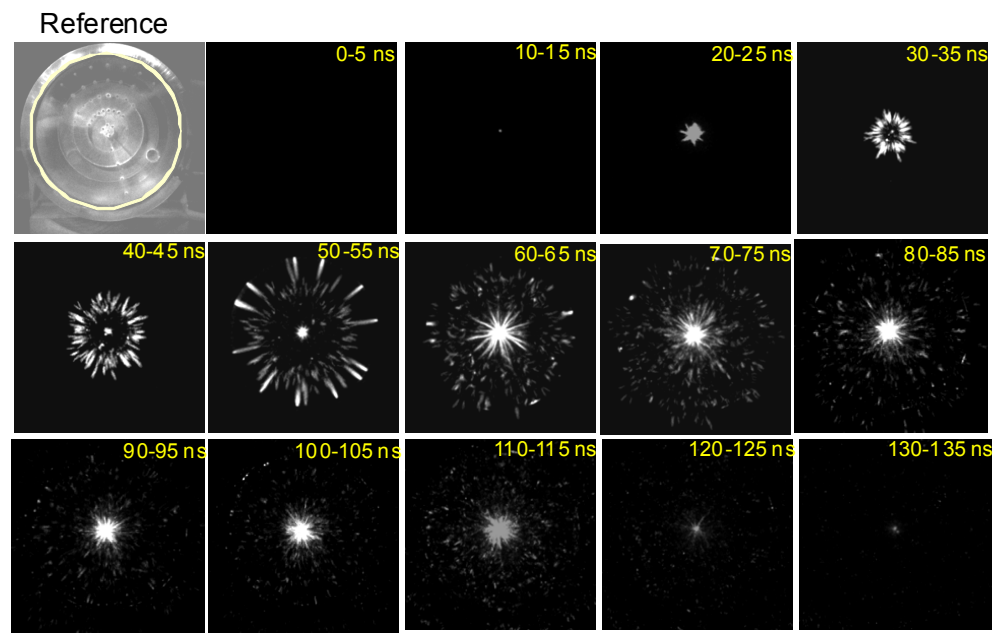

Fig. 3. Images of light emissions from positive pulsed streamer discharges as a function of time after initiation of the discharge current. Peak voltage: $72 \mathrm{kV} .100 \mathrm{~ns}$ of pulse duration. Outer cylinder diameter: $76 \mathrm{~mm}$. The bright areas of the framing images show the position of the streamer heads during the exposure time of $5 \mathrm{~ns}$. 


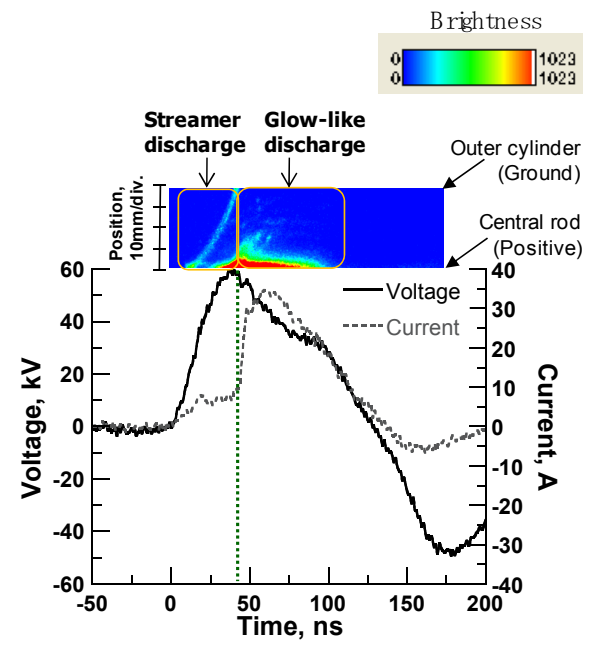

(a) Positive pulsed streamer discharge at $30 \mathrm{kV}$ charging voltage.

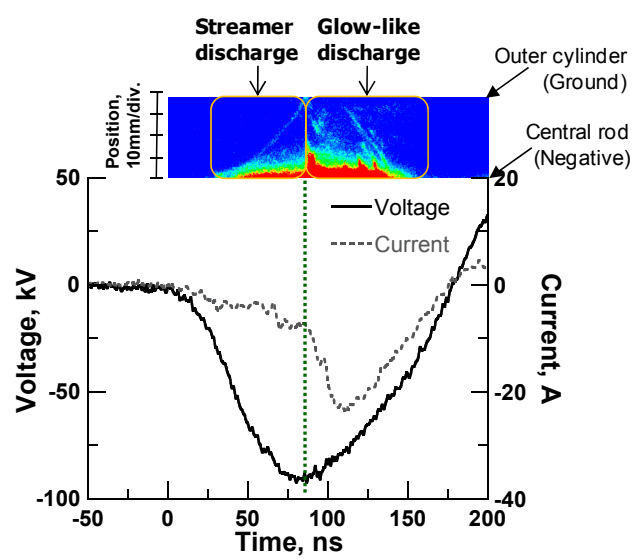

(b) Negative pulsed streamer discharge at $-30 \mathrm{kV}$ charging voltage.

Fig. 4. Typical applied voltage and discharge current in the electrode gap, and streak image for the generator with 100 ns of pulse duration. Voltage was measured using a voltage divider, discharge current through the electrodes was measured using a current transformer. The vertical direction of the streak image corresponds to the position within the electrode gap. The bottom and top ends of the streak image correspond to the central rod and the surface of the grounded cylinder, respectively. The horizontal direction indicates time progression. The sweep time for one frame of exposure was fixed at $200 \mathrm{~ns}$. 


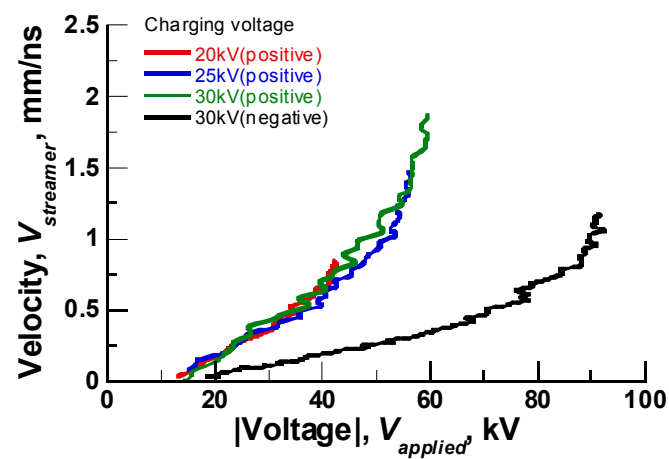

Fig. 5. Dependence of the velocity of the streamer heads on the applied voltage to the rod electrode for both positive and negative pulsed streamer discharge cases. $100 \mathrm{~ns}$ of pulse duration.

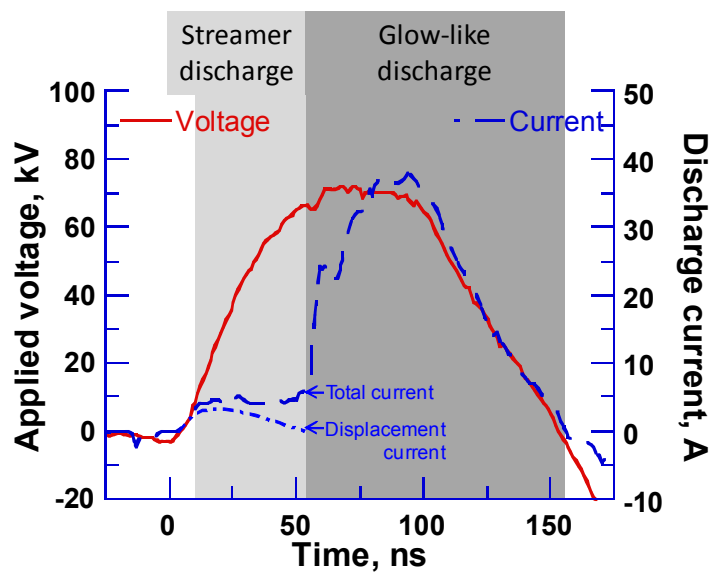

(a) applied voltage and discharge current through the electrode gap. 100 ns of pulse duration. Displacement current was calculated from $\left(C_{\text {reactor }} \times d V_{t} / d t\right)$ where $C_{\text {reactor }}$ is the capacitance of the reactor and $V_{t}$ is the voltage from the waveform. 


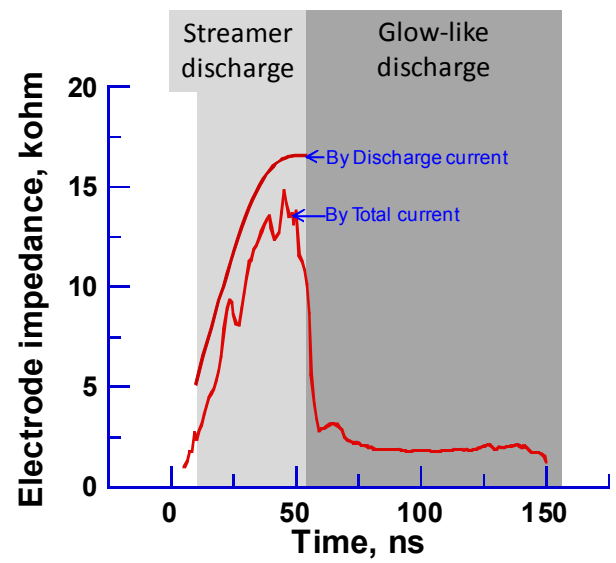

(b) Electrode gap impedance calculated from Fig. 6 (a).

Fig. 6. Change of electrode impedance during $100 \mathrm{~ns}$ discharge propagation process.

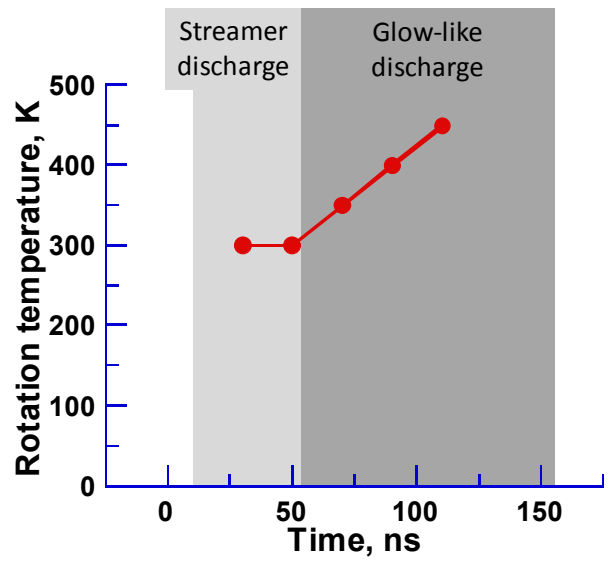

Fig. 7. Time dependence of the gas temperature around the central rod in a coaxial electrode geometry during a $100 \mathrm{~ns}$ pulsed discharge.

\section{Generation of Nano-seconds Pulsed Streamer Discharge (Pulse duration of $5 \mathrm{~ns}$ with $2.5 \mathrm{~ns}$ rise and fall time)}

A nano-seconds pulsed power generator (NS-PG) having a pulse duration of $5 \mathrm{~ns}$ and maximum applied voltage of $100 \mathrm{kV}$ was developed by Namihira et al. in early 2000s [39]. The generator consists of a coaxial high-pressure spark gap switch (SGS) as a low inductance self-closing switch, a triaxial Blumlein as a pulse-forming line, and a voltage transmission line which transmit energy from the triaxial Blumlein line to the load. The SGS was filled with $\mathrm{SF}_{6}$ gas, and the output voltage from the generator is regulated by varying the pressure of the $\mathrm{SF}_{6}$ gas. Gap distance of the SGS was fixed. The triaxial Blumlein consists of an inner 
rod conductor, a middle cylinder conductor, and an outer cylinder conductor. The inner, the middle, and the outer conductors of the triaxial Blumlein were concentric. The triaxial Blumlein and the transmission line were filled with silicone oil as an insulation and dielectric medium. For operation of the NS-PG, the middle conductor of the triaxial Blumlein was charged through a charging port that was connected to a pulsed charging circuit. The pulsed charging circuit consists of a dc source, a charging resistor, a capacitor, a thyratron switch, and a pulse transformer. The outer conductor was grounded. A capacitive voltage divider was mounted on the transmission line to measure output voltage of the NSPG. The discharge current through the electrode was measured using a current monitor which was located after the transmission line. Polarity of the NS-PG output voltage could be controlled as either positive or negative by changing the polarity of output of the pulse transformer in the charging circuit. Typical applied voltage and current waveforms with an impedance matched resistive load are shown in Fig.8. The rise and fall times, and the pulse width are approximately $2.5 \mathrm{~ns}$ and $5 \mathrm{~ns}$ for both polarities.

Framing images and streak images of the discharge phenomena caused by the NS-PG are shown in Fig. 9 and Fig. 10, respectively. In case of positive pulsed streamer discharge, the streamer heads were generated near the central rod electrode and then propagated toward the grounded cylinder electrode in all radial direction of the coaxial electrode. The time duration of the streamer discharge was within $6 \mathrm{~ns}$. At around $5 \mathrm{~ns}$, emission from a secondary streamer discharge was observed in the vicinity of the central rod electrode. This is attributed to the strong electric field at the rod. Finally, emission from the pulsed discharge disappeared at around 7ns, and the glow-like discharge phase was not observed. Similar propagation process of a discharge can be confirmed from the negative pulsed discharge. The average propagation velocity of the streamer heads calculated by equation (5) was $6.1 \sim 7.0 \mathrm{~mm} / \mathrm{ns}$ for a positive peak applied voltage of $67 \sim 93 \mathrm{kV}$ of and $6.0 \sim 8.0$ $\mathrm{mm} / \mathrm{ns}$ for a negative peak applied voltage $-67 \sim-80 \mathrm{kV}$, respectively. The average velocity of the streamer heads slightly increased at higher applied voltages but showed no significant difference between positive and negative voltage polarities. Since the propagation velocity of the streamer heads is $0.1 \sim 1.2 \mathrm{~mm} / \mathrm{ns}$ for a $100 \mathrm{~ns}$ pulsed discharge, five times faster velocity is observed with the NS-PG (Fig.11). The streamer head always has the largest electric field in the electrode gap, and it is known streamer heads with higher value electric fields have a faster propagation velocity [40]. Therefore, it is understood that the faster propagation velocity of the streamer head means that the streamer head has more energetic electrons and higher energy. Consequently, the electron energy generated by nano-seconds pulsed discharge is higher than that of a general pulsed discharge [41], [42]. Here it should be mentioned that the voltage rise time (defined between 10 to $90 \%$ ) was 25 ns for a $100 \mathrm{~ns}$ general pulsed discharge and $2.5 \mathrm{~ns}$ for the 5 ns nano-seconds pulsed discharge. Therefore, the faster propagation velocity of streamer head might be affected by the faster voltage rise time. The dependence of the propagation velocity of the streamer heads on the voltage rise time was studied by controlling the winding ratio of the pulse transformer (PT) that connected after the pulse generator. The dependence of the velocity of the streamer heads on the applied voltage to the rod electrode for different voltage rise time is shown in Fig. 12. From Fig.12, the propagation velocity of the streamer heads for 1:3 is approximately one and a half times faster than that of 3:9 PT winding ratio at the same applied voltage. Hence, the reason of the faster propagation velocity resulted in the nanoseconds pulsed discharge is due to the faster voltage rise time in comparison of the general 
pulsed discharge [43]. Another interesting phenomenon of the nano-seconds pulsed discharge is the polarity dependence of the streamer propagation velocity. Generally, the velocity of a streamer head is faster for positive voltage application. In case of $100 \mathrm{~ns}$ pulsed discharges, the velocity for a negative streamer was approximately half that of a positive streamer. However, no significant difference was observed in the nano-seconds discharge by NS-PG for different polarities.

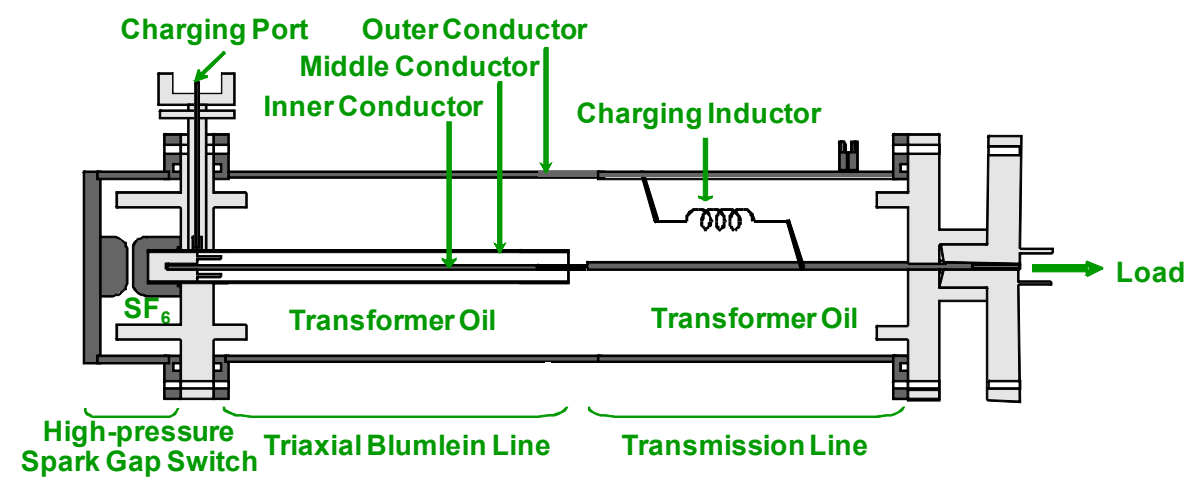

(a) Schematic diagram

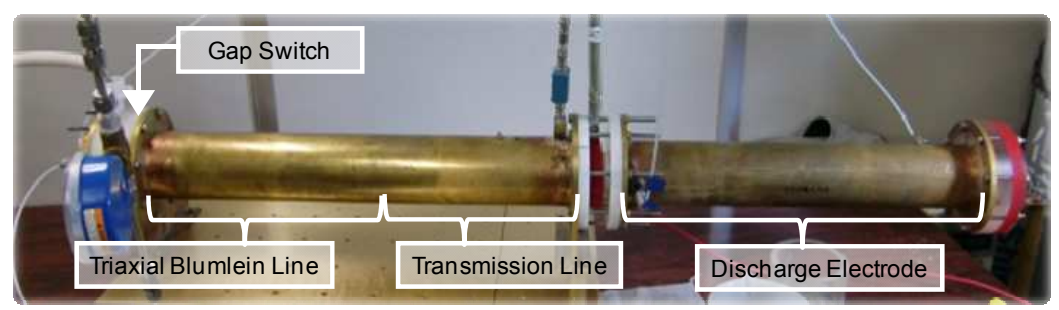

(b) Still image

Fig. 8. Schematic diagram (a) and a still image (b) of the nano-seconds pulsed generator having pulse duration of $5 \mathrm{~ns}$. 


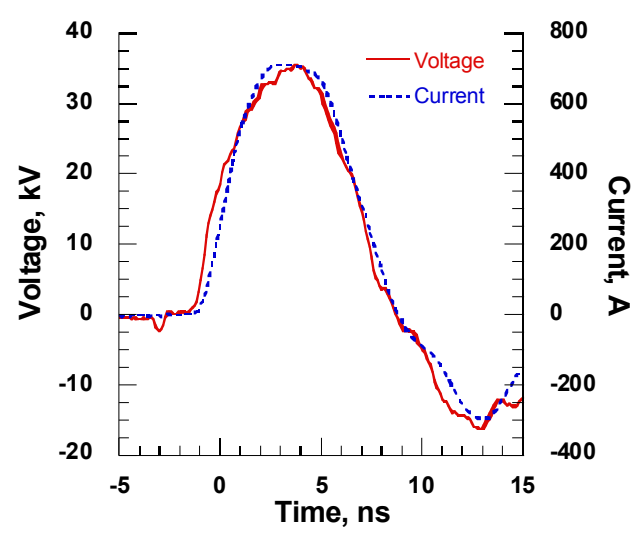

Fig. 8. Typical applied voltage and current waveforms for the nano-seconds pulsed generator with $5 \mathrm{~ns}$ of pulse duration. Load is impedance matched non-inductive resistor.
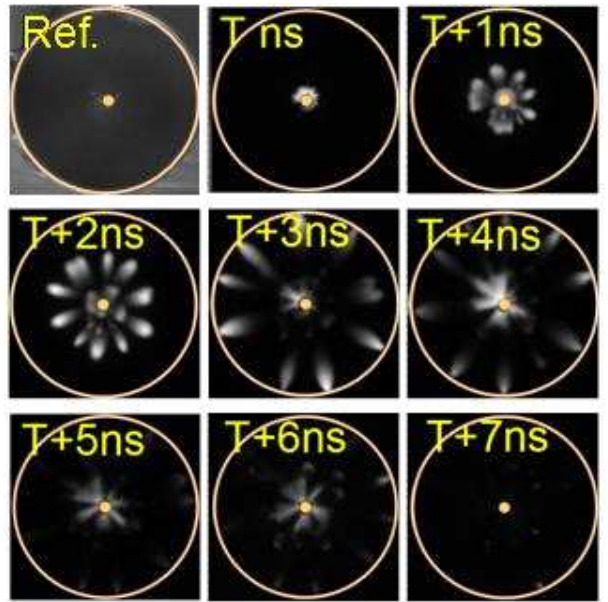

Fig. 9. Images of light emissions from positive pulsed streamer discharges as a function of time after initiation of the discharge current. Peak voltage: $100 \mathrm{kV} .5 \mathrm{~ns}$ of pulse duration. Outer cylinder diameter: $76 \mathrm{~mm}$. The bright areas of the framing images show the position of the streamer heads during the exposure time of $200 \mathrm{ps}$. 


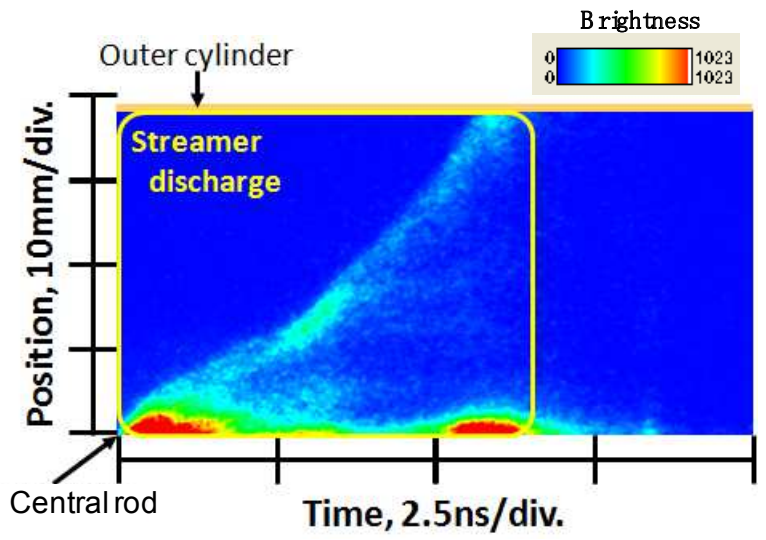

(a) Positive polarity. Peak voltage: $93 \mathrm{kV}$.

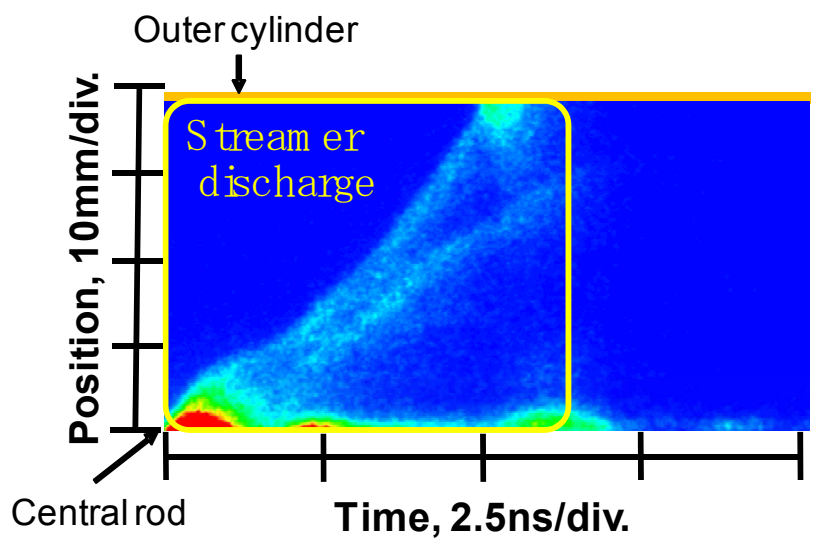

(b) Negative polarity. Peak voltage: $-80 \mathrm{kV}$.

Fig. 10. Streak images for the nano-seconds pulsed generator with 5 ns of pulse duration. The vertical direction of the streak image corresponds to the position within the electrode gap. The bottom and top ends of the streak image correspond to the central rod and the surface of the grounded cylinder, respectively. The horizontal direction indicates time progression. The sweep time for one frame of exposure was fixed at $10 \mathrm{~ns}$. 


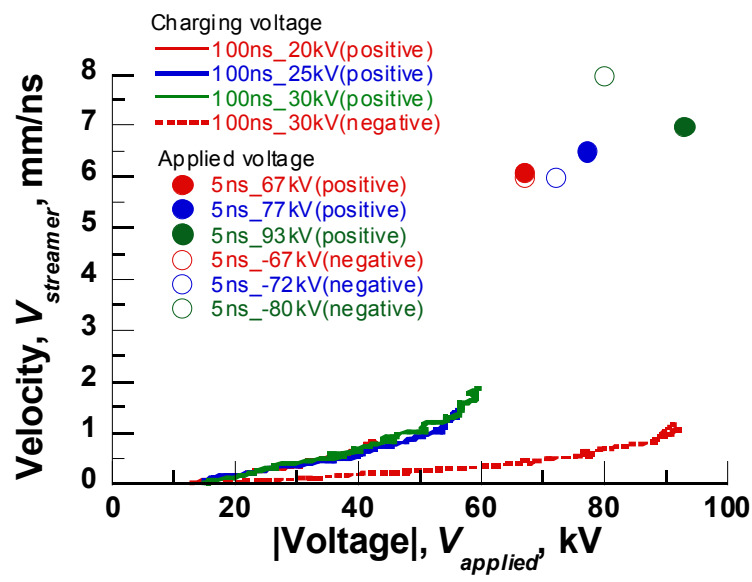

Fig. 11. Dependence of the velocity of the streamer heads on the applied voltage to the rod electrode for both positive and negative streamer discharge cases. (Comparison between general pulsed discharge and nano-seconds pulsed discharge)

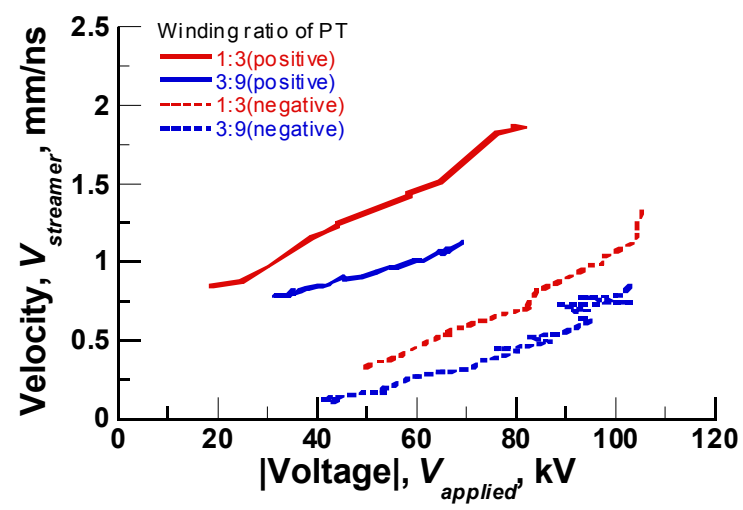

Fig. 12. Dependence of the velocity of the streamer heads on the applied voltage to the rod electrode for different voltage rise time. A three-staged Blumlein line generator with pulse duration of $200 \mathrm{~ns}$ was used to generate pulsed discharges. The voltage rise time was controlled by changing the winding ratio of the pulse transformer (PT) which connected after the Blumlein line generator. The winding ratio of primary to secondary windings of the PT was designed as 1:3 or 3:9. $30 \mathrm{kV}$ of charging voltage.

\section{Comparison of General Pulsed Streamer Discharge and the Nano-seconds Pulsed Streamer Discharge}

A comparison of the discharge characteristics are shown in Table 1. In general, streamer and glow-like discharges were observed in a pulsed discharge with a $100 \mathrm{~ns}$ pulse duration. In the glow-like discharge phase, a change of the electrode gap impedance and rise of the gas temperature occurred. Those factors could induce energy loss in the plasma processing 
system for gas treatment. On the other hand, the discharge propagation finished before it shifted to the glow-like discharge phase in case of a nano-seconds pulsed discharge. The pulse duration of the NS-PG was approximately $5 \mathrm{~ns}$ with over $90 \mathrm{kV}$ of peak applied voltage. The streamer propagation velocity by NS-PG is about five times faster than that of the general pulsed discharge, and has little difference between positive and negative voltage polarities. These results might be due to the very fast voltage rise and fall time of NS-PG. Because the electron energy in the streamer head generated by NS-PG is thought to be relatively high, the plasma-enhanced chemical reactions for gas decomposition and generation are expected to be more effective. Therefore, the energy transfer efficiency from the charging circuit to discharge reactor can be estimated to be higher than that of a general pulsed discharge. It can be concluded that a nano-seconds pulsed discharge is a promising method as a non-thermal plasma processing technique.

\begin{tabular}{|c|c|c|c|}
\hline & \multicolumn{2}{|c|}{$\begin{array}{c}\text { General } \\
\text { pulsed streamer discharge }\end{array}$} & $\begin{array}{c}\text { Nano-seconds } \\
\text { pulsed streamer discharge }\end{array}$ \\
\hline Voltage rise time & \multicolumn{2}{|c|}{$25 \mathrm{~ns}$} & $2.5 \mathrm{~ns}$ \\
\hline Voltage fall time & \multicolumn{2}{|c|}{$25 \mathrm{~ns}$} & $2.5 \mathrm{~ns}$ \\
\hline Pulse duration & \multicolumn{2}{|c|}{$100 \mathrm{~ns}$} & $5 \mathrm{~ns}$ \\
\hline Discharge phase & Streamer & Glow-like & Streamer \\
\hline $\begin{array}{c}\text { Propagation } \\
\text { velocity of } \\
\text { streamer heads } \\
\text { (Vapplied-peak) }\end{array}$ & $\begin{array}{c}0.1 \sim 1.2 \mathrm{~mm} / \mathrm{ns} \\
(10 \sim 60 \mathrm{kV})\end{array}$ & - & $6.1 \sim 7.0 \mathrm{~mm} / \mathrm{ns}$ \\
$(67 \sim 93 \mathrm{kV})$ \\
\hline $\begin{array}{c}\text { Electrode } \\
\text { impedance }\end{array}$ & $5 \sim 17 \mathrm{k} \Omega$ & $2 \mathrm{k} \Omega$ & $6.0 \sim 8.0 \mathrm{~mm} / \mathrm{ns}$ \\
$(\mathrm{L}=10 \mathrm{~mm})$ & $(\mathrm{L}=10 \mathrm{~mm})$ & $0.80 \mathrm{kV})$ \\
\hline
\end{tabular}

Table 1. A comparison of the discharge characteristics between general pulsed streamer discharge and nano-seconds pulsed streamer discharge.

\section{Characterization Map of NO Removal for Different Discharge Methods}

Characteristic map of NO removal based on different discharge methods is given in Fig. 13. [44]. Comparison of nano-seconds pulsed discharge, dielectric barrier discharge (DBD) and pulsed corona discharge are displayed under the same condition of $200 \mathrm{ppm}$ of initial NO concentration. NO removal ratio, $N O_{R}$ in \%, and removal efficiency, $N O_{E}$ in $\mathrm{mol} / \mathrm{kWh}$, are given by equation (7) and (8):

$$
\begin{gathered}
N O_{R}=\frac{N O_{i}-N O_{f}}{N O_{i}} \times 100 \\
N O_{E}=\frac{G \times \frac{1}{22.4}[\mathrm{~mol} / l] \times N O_{R} \times 60[\mathrm{~min} / h]}{f \times E \times 10^{3}}
\end{gathered}
$$

where $N O_{i}$ (in ppm), $N O_{f}$ (in ppm), G (l/min), $f$ (pps) and $E(\mathrm{~J} /$ pulse) are the initial and the final concentrations of $\mathrm{NO}$ in the exhaust gas, gas flow rate, pulse repetition rate and input energy into discharge electrode per pulse $(\oint V I d t)$, respectively. 
The characterization map is based on input energy to discharge electrode. In Fig. 13, the right-upper region identifies the better performance of NO removal method. Nano-seconds pulsed discharge shows the best energy efficiency than other discharge methods.

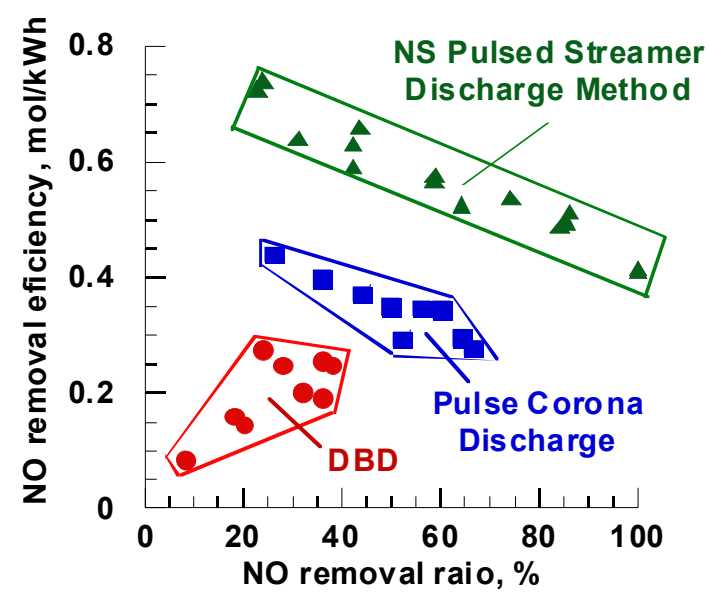

Fig. 13. Characteristic map of NO removal based on different discharge methods under the same condition of $200 \mathrm{ppm}$ of initial NO concentration.

\section{Ozone Generation}

Ozone is known as a powerful oxidizing agent, far better than chlorine, which exists in nature. It is also a gas that does not generate by products since ozone decays to ordinary diatomic oxygen. Wide interests are focused on ozone generation studies for practical applications such as treatment of drinking and waste water, air purification, decoloration, bactericide and sterilization of food products etc [45], [46]. Recently, the medical usage of ozone has been widely studied in Europe, mainly in the fields of internal medicine, pediatrics, obstetrics and gynecology, and otorhinology [47]. Therefore, much atttention has been paid for developing an energy-efficient ozonizer. However, ozone is an unstable agent which decays into oxygen at high concentrations, so that on-site production of ozone is desired. Several methods are available for ozone production: UV, electrolysis, and discharge method [48]. The leading method is the dielectric barrier discharge (DBD) which has been studied extensively using ac applied voltages. Several studies of ozone production using corona discharges incorporating dielectric barriers have been reported. However, the relatively long time duration of the applied voltage of a DBD leads to energy loss since not only electrons but also ions are accelerated, which generate heating losses during ozone production. Moreover, cooling systems are required for the dielectric materials resulting in further energy loss. Therefore, pulsed discharges, as distinguished without dielectric materials and only accelerated electrons, have been studied for ozone production in recent years. 


\subsection{Ozone Generation Using Pulsed Discharges}

Pulsed discharges having different pulse duration, 50, 100, and $150 \mathrm{~ns}$, were applied for ozone generation experiments (Fig. 14). The results showed that pulsed discharge with shorter duration has higher energy efficiency of ozone generation. This is because that the glow-like discharge resulted in the longer pulsed power has negative influences for ozone generation; ozone molecules attach low energy electron, typically $0 \sim 2.5 \mathrm{eV} \mathrm{[49]-[51],} \mathrm{during}$ the glow-like discharge phase of the pulsed discharge, so that the ozone molecules were dissociated by the attachment of the low energy electrons. Here, it should be mentioned that the energetic electron during the streamer discharge phase is around $5 \sim 10 \mathrm{eV}$ [52].

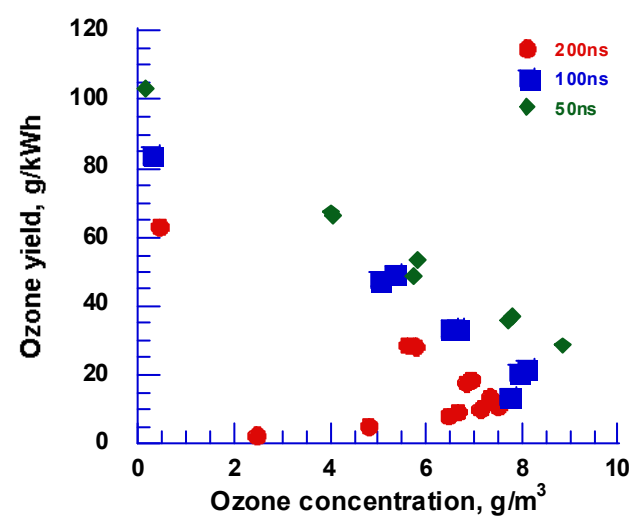

Fig. 14. Characteristic map of ozone generation based on different pulse duration under same positive applied voltages. Dry air was fed into the ozone generation at $1.0 \mathrm{l} / \mathrm{min}$ of gas flow rate was fixed at $273 \mathrm{~K}$ and $0.1 \mathrm{MPa}$.

\subsection{Characterization Maps of Ozonizers Based on Different Discharge Methods}

Characterization maps of ozonizers based on different discharge methods (nano-seconds pulsed discharge, DBD, DBD with narrow-gap, surface discharge, pulsed corona discharge, DC corona, superimposed discharge methods and a commercial ozonizer) were presented with oxygen-fed and air-fed cases (Fig. 15) [53]-[72]. The production yield of ozone, $\eta$ in $\mathrm{g} / \mathrm{kWh}$, was determined from

$$
\eta=\frac{c \cdot r \cdot 60}{f \cdot E}
$$

where $c$ is the concentration of ozone (in $\left.\mathrm{g} / \mathrm{Nm}^{3}\right), r$ is the gas flow rate in the discharge reactor (in $1 / \mathrm{min}$ ), $f$ is the pulse repetition rate (in pps, pulses/second) and $E$ is the input energy to the reactor per pulse (J/pulse). It should be noted that $0.048 \mathrm{~kg}$ of ozone is equivalent to $1 \mathrm{~mol}$ and $22.4 \mathrm{~L}$ at $1.01 \times 10^{5} \mathrm{~Pa}$ and $273 \mathrm{~K}$. Equation (9) can also give the yield in mol/ $\mathrm{kWh}$ by dividing $\eta(\mathrm{g} / \mathrm{kWh})$ by 48 . The concentration of ozone can be given in ppm by multiplying $c\left(\mathrm{~g} / \mathrm{Nm}^{3}\right)$ by 467 . In Fig. 15, the right-upper region identifies the better performance of an ozonizer. It should be noted that the ozone yield resulting from the commercial ozonizer was evaluated from the plug-in energy while the others were 
examined using the discharge energy. The nano-seconds pulsed discharge showed the highest ozone yield in the characterization maps for both the oxygen-fed and air-fed cases, where the highest ozone yield were 544 and $239 \mathrm{~g} / \mathrm{kWh}$ in the oxygen-fed and air-fed cases, respectively. A summary of the characteristics map of ozonizer based on the different discharge methods (Fig. 15) is shown in Table 2 [73].

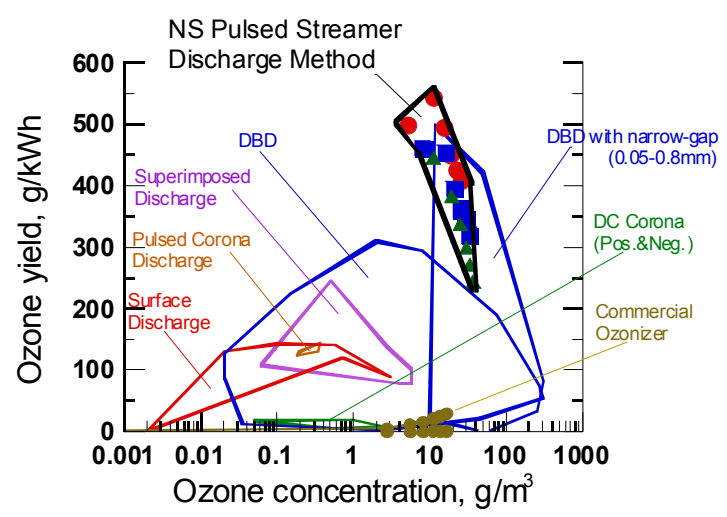

(a) Oxygen-fed

(b) Air-fed

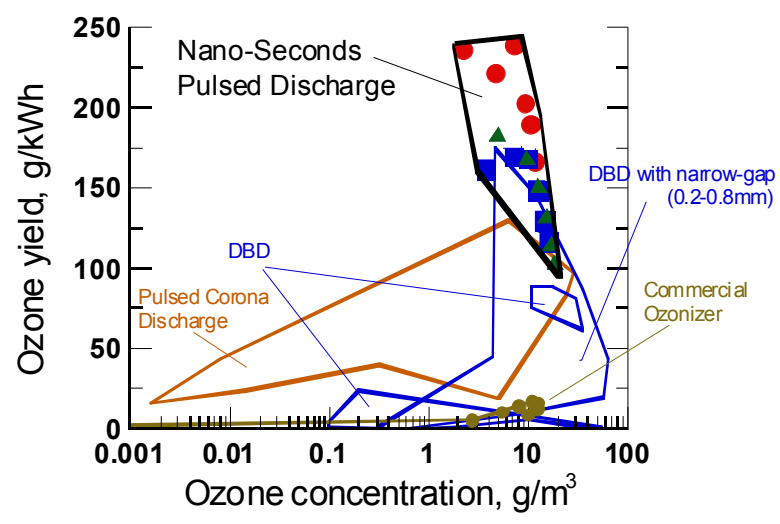

Fig. 15. Characteristics map of ozonizers based on different discharge methods.

\begin{tabular}{|l|c|c|c|c|}
\hline & \multicolumn{2}{|c|}{ Oxygen-fed } & \multicolumn{2}{c|}{ Air-fed } \\
\hline Discharge method Characteristics & $\begin{array}{c}\text { Max.ozone } \\
\text { yield, } \\
\mathrm{g} / \mathrm{kWh}\end{array}$ & $\begin{array}{c}\text { Available } \\
\text { ozone } \\
\text { concentration, } \\
\mathrm{g} / \mathrm{m}^{3}\end{array}$ & $\begin{array}{c}\text { Max.ozone } \\
\text { yield, } \\
\mathrm{g} / \mathrm{kWh}\end{array}$ & $\begin{array}{c}\text { Available } \\
\text { ozone } \\
\text { concentration, } \\
\mathrm{g} / \mathrm{m}^{3}\end{array}$ \\
\hline Nano-Seconds Pulsed Discharge & 544 & $4.9 \sim 36.5$ & 239 & $2.2 \sim 18.3$ \\
\hline DC Corona & 19 & $0.05 \sim 2$ & - & - \\
\hline Pulsed Corona Discharge & 145 & 0.10 .3 & 130 & $0.001 \sim 28$ \\
\hline Surface Discharge & 143 & $0.002 \sim 3$ & - & - \\
\hline DBD & 310 & $0.02 \sim 299$ & 88 & $0.1 \sim 55$ \\
\hline
\end{tabular}




\begin{tabular}{|l|c|c|c|c|}
\hline DBD with narrow-gap & 500 & $10 \sim 300$ & 175 & $0.3 \sim 62$ \\
\hline Superimposed Discharge & 138 & $0.06 \sim 6$ & - & - \\
\hline Commercial ozonizer & 30.5 & $\sim 16$ & $\sim 17$ & $\sim 10$ \\
\hline $\begin{array}{l}\text { Commercial ozonizer } \\
\text { (System evaluation, with plug-in energy) }\end{array}$ & 1.9 & $\sim 16$ & - & - \\
\hline
\end{tabular}

Table 2. Summary of the characteristics map of ozonizer based on different discharge methods.

\section{Conclusion}

A discharge with pulse duration of 100 ns, the general pulsed streamer discharge, shows two discharge phases: a streamer discharge which initiates in the vicinity of the central electrode and propagates toward the outer electrode; and a glow-like discharge which is generated after full development of the streamer discharge. It was also observed that the plasma impedance was different for the streamer and the glow-like discharges. Moreover, a rise of the gas temperature occurred during the glow-like discharge phase. These factors could induce energy losses due to the impedance mismatching between the pulsed power generator and discharge reactor, with gas thermalization of plasma-enhanced chemical reactions during gas treatment. On the other hand, the discharge with pulse duration of $5 \mathrm{~ns}$, nano-seconds pulsed streamer discharge, indicates that the discharge history finishes before it shifts to the glow-like discharge phase. Consequently, the impedance matching between the power generator and discharge reactor can be improved and the gas heating problem can be minimized. It can be concluded that a nano-seconds pulsed discharge is a promising method as a non-thermal plasma processing technique [74], [75].

\section{References}

[1] Penetrante, B. M. \& Schultheis, S. E., (1993). Nonthermal plasma techniques for pollution control, Fundamentals and Supporting Technologies, pt. A, 1-393, Springer-Verlag, New York

[2] Penetrante, B. M. \& Schultheis, S. E., (1993). Nonthermal plasma techniques for pollution control, Electron Beam and Electrical Discharge Processing, pt. B, 1-397, SpringerVerlag, New York

[3] Urashima, K.; Chang, J.-S.; Park, J.-Y.; Lee, D.-C.; Chakrabarti, A. \& Ito, T. (1998). Reduction of NO from natural gas combustion flue gases by corona discharge radical injection techniques, IEEE Trans. Indust. Appl., Vol. 34, 934-939

[4] Penetrante, B. M. (1993). Pollution control applications of pulsed power technology, Proceedings of 9th IEEE Int. Pulsed Power Conf., pp. 1-5, Albuquerque, NM, USA

[5] Gallimberti, I. (1988). Impulse corona simulation for flue gas treatment, Pure Appl. Chem., Vol. 60, 663-674

[6] Urashima, K.; Chang, J.-S. \& Ito, T. (1997). Reduction of NO from combustion flue gases by superimposed barrier discharge plasma reactors, IEEE Trans. Indust. Appl., Vol. 33, 879-886

[7] Bhasavanich, D.; Ashby, S.; Deeney, C. \& Schlitt, L. (1993). Flue gas irradiation using pulsed corona and pulsed electron beam technology, Proceedings of 9th IEEE Int. Pulsed Power Conf., pp. 441-444, Albuquerque, NM, USA 
[8] Chang, J.-S.; Looy, P. C.; Nagai, K.; Yoshioka, T.; Aoki, S. \& Maezawa, A. (1996). Preliminary pilot plant tests of a corona discharge-electron beam hybrid combustion flue gas cleaning system, IEEE Trans. Indust. Appl., Vol. 32, 131-137

[9] Penetrante, B. M.; Hsiao, M. C.; Bardsley, J. N.; Merritt, B. T.; Vogtlin, G. E.; Wallman, P. H.; Kuthi, A.; Burkhart, C. P. \& Bayless, R. J. (1995). Electron beam and pulsed corona processing of volatile organic compounds and nitrogen oxides, Proceedings of 10th IEEE Int. Pulsed Power Conf., 144-149, Albuquerque, NM, USA

[10] Penetrante, B. M. (1997). Removal of NO from diesel generator exhaust by pulsed electron beams, Proceedings of 11th IEEE Int. Pulsed Power Conf., 91-96, Baltimore, MD, USA

[11] Rosocha, L.; Anderson, G. K.; Bechtold, L. A.; Coogan, J. J.; Heck, H. G.; Kang, M.; M. McCulla, M.; M. Tennant, M. \& Wantuck, P. J. (1993). Treatment of hazardous organic wastes using silent discharge plasmas, In: Non-Thermal Plasma Techniques for Pollution Control, Penetrante, B. M. \& Schultheis S. E. (Ed.), pt. B, 281-308, Springer-Verlag, New York

[12] Masuda, S. (1988). Pulse corona induced plasma chemical process: A horizon of new plasma chemical technologies, Pure Appl. Chem., Vol. 60, 727-731

[13] Akiyama, H.; Kawamura, K.; Takeshita, T.; Katsuki, S.; Maeda, S.; Tsukamoto, S. \& Murata, M. (1995). Removal of NO using discharges by pulsed power, Proceedings of 10th IEEE Int. Pulsed Power Conf., pp. 133-137, Albuquerque, NM, USA

[14] Dinelli, G.; Civitano, L. \& Rea, M. (1990). Industrial experiments on pulse corona simultaneous removal of $\mathrm{NO}$ and SO from flue gas, IEEE Trans. Indust. Appl., Vol. $26,535-541$

[15] Chang, J.-S.; Lawless, P. A. \& Yamamoto, T. (1991). Corona discharge processes, IEEE Trans. Plasma Sci., Vol. 19, 1152-1166

[16] Heesch, E. J. M. Van; Smulders, H. W. M.; Paasen, S. V. B. Van; Blom, P. P. M.; Gompel, F. M. Van; Staring, A. J. P. M. \& Ptasinski, K. J. (1997). Pulsed corona for gas and water treatment, Proceedings of 11th IEEE Int. Pulsed Power Conf., pp. 103-108, Baltimore, MD, USA

[17] Clements, J. S.; Mizuno, A.; Finney, W. C. \& Davis, R. H. (1989). Combined removal of $\mathrm{SO}_{2}, \mathrm{NO}_{\mathrm{x}}$ and fly ash from simulated flue gas using pulsed streamer corona, IEEE Trans. Indust. Appl., Vol. 25, 62-69

[18] Masuda S. \& Nakao, H. (1995). Control of NO by positive and negative pulsed corona discharges, IEEE Trans. Indust. Appl., Vol. 26, 374-383

[19] Mizuno, A.; Shimizu, K.; Chakrabarti, A.; Dascalescu, L. \& Furuta, S. (1995). NO removal process using pulsed discharge plasma, IEEE Trans. Indust. Appl., Vol. 31, 957-963

[20] Akiyama, H. (1995). Pollution control by pulsed power, Proceedings of 1995 Int. Power Electron. Conf., 1397-1400, Yokohama, Kanagawa, Japan

[21] Tsukamoto, S.; Namihira, T.; Wang, D.; Katsuki, S.; Akiyama, H.; Nakashima, E.; Sato, A.; Uchida, Y. \& Koike, M. (1999). $\mathrm{NOx}$ and $\mathrm{SO}_{2}$ removal by pulsed power at a thermal power plant, Proceedings of 12th IEEE Int. Pulsed Power Conf., Monterey, CA, USA

[22] Masuda S. \& Nakao, H. (1990). Control of NOx by positive and negative pulse corona discharges, IEEE Trans. Indust. Appl., Vol. 26, 374-383 
[23] Tsukamoto, S.; Namihira, T.; Wang, D.; Katsuki, S.; Akiyama, H.; Nakashima, E.; Sato, A.; Uchida, Y. \& Koike, M. (1999). Pollution control of actual flue gas using pulsed power at a thermal power plant (in Japanese), Trans. IEEJ, Vol. 119-A, 984-989

[24] Namihira, T.; Wang, D.; Tsukamoto, S.; Katsuki, S. \& Akiyama, H. (1999). Effect of gas composition for $\mathrm{NO}_{\mathrm{X}}$ removal using pulsed power (in Japanese), Trans. IEEJ, Vol. 119-A, 1190-1195

[25] Hirota, K.; Sakai, H.; Washio M. \& Kojima, T. (2004). Application of Electron Beams for the Treatment of VOC Streams, Ind. Eng. Chem. Res., Vol. 43, 1185-1191

[26] Nozaki, T.; Miyazaki, Y.; Unno, Y. \& Okazaki, K. (2001). Energy distribution and heat transfer mechanism in atmospheric pressure non-equilibrium plasmas, Journal of Physics D: Applied Physics, Vol. 34, No. 23, 3383-3390

[27] Wang. D.; Namihira, T.; Fujiya, K.; Katsuki S. \& Akiyama, H. (2004). The reactor design for diesel exhaust control using a magnetic pulse compressor, IEEE Transactions on Plasma Science, Vol. 32, No. 5, 2038-2044

[28] Namihira, T.; Tsukamoto, S.; Wang, D.; Katsuki, S.; Hackam, R.; Akiyama, H.; Uchida, Y. \& Koike, M. (2000). Improvement of NO removal efficiency using short width pulsed power, IEEE Trans. Plasma Sci., Vol. 28, 434-442

[29] Puchkarev V. \& Gundersen, M. (1997). Energy efficient plasma processing of gaseous emission using a short pulse discharge, Appl. Phys. Lett., Vol. 71, No. 23, 3364-3366

[30] Penetrante, B. M. (1993). Plasma chemistry and power consumption in nonthermal deNOx, In: Nonthermal Plasma Techniques for Pollution Control, Penetrante B. M. \& Schultheis, S. E. (Ed.), pt. A, 65-90, Springer-Verlag, 1993, New York

[31] Penetrante B. M. \& Schultheis, S. E. (1993). Nonthermal plasma techniques for pollution control, Fundamentals and Supporting Technologies, pt. A, 1-393, Springer-Verlag, New York

[32] Hackam R. \& Akiyama, H. (2000). Air pollution control by electrical discharges, IEEE Trans. Dielect. Elect. Insulation, Vol. 7, 654-683

[33] Urashima K. \& Chang, J. S. (1997) The effect of ammonia injection rate and discharge power on the reduction of NO from combustion flue gas by superimposing barrier discharge reactors, J. Adv. Oxid. Technol., Vol. 2, 286-293

[34] Urashima, K.; Chang, J. S. \& Ito, T. (1997). Reduction of NO from combustion flue gases by superimposed barrier discharge plasma reactions, IEEE Trans. Ind. Applicat., Vol. 33, 879-886

[35] Namihira, T.; Wang, D.; Katsuki, S.; Hackam R. \& Akiyama, H. (2003). Propagation velocity of pulsed streamer discharges in atmospheric air, IEEE Transactions on Plasma Science, Vol.31, No.5, 1091-1094

[36] Tochikubo F. \& Teich, T. H. (2000). Optical Emission from a Pulsed Corona Discharge and Its Associated Reactions, Jpn. J. Appl. Phys., Vol. 39, 1343-1350

[37] Sakamoto, T.; Matsuura, H. \& Akatsuka, H. (2007). Spectroscopic study on the vibrational populations of $\mathrm{N}_{2} \mathrm{C}^{3} \Pi$ and $\mathrm{B}^{3} \Pi$ states in a microwave nitrogen discharge, Journal of Applied Physics, Vol.101, 023307-1-7

[38] Wang, D.; Jikuya, M.; Yoshida, S.; Namihira, T.; Katsuki, S. \& Akiyama, H. (2007). Positive- and Negative-Pulsed Streamer Discharges Generated by a $100-n s$ Pulsed Power in Atmospheric Air, IEEE Transactions on Plasma Science, Vol.35, No.4, 10981103 
[39] Wang, D.; Namihira, T.; Katsuki S. \& Akiyama, H. (2004). Ultra-short pulse generator for environmental control, Proceedings of 15th International Conference on Gas Discharges and Their Applications, Vol.2, pp. 709-712, Toulouse, France

[40] Tochikubo F. \& Arai, H. (2002). Numerical Simulation of Streamer propagation and Radical Reaction in Positive Corona Discharge in $\mathrm{N}_{2} / \mathrm{NO}$ and $\mathrm{N}_{2} / \mathrm{O}_{2} / \mathrm{NO}$, Jpn. J. Appl. Phys., Vol. 41, 844-852

[41] Wang, D.; Namihira T. \& Akiyama, H. (2009). Pulsed discharge plasma generated by nano-seconds pulsed power in atmospheric air, Proceedings of 17th IEEE International Pulsed Power Conference, Washington, DC, USA

[42] Wang, D; Okada, S; Matsumoto, T; Namihira, T \& Akiyama, H. (2010). Pulsed Discharge Induced by Nanosecond Pulsed Power in Atmospheric Air, IEEE Transactions on Plasma Science, in press

[43] Wang, D; Namihira, T; Matsumoto, T; Okada, S \& Akiyama, H. (2010). Different Discharge Phenomena Between General and Nano-Seconds Pulsed Discharges, Proceedings of The seventh International Symposium on Non-Thermal Plasma Technology, $X-5$, John's, Newfoundland, Canada

[44]Kim, Y. (2004). Experimental and Numerical Analysis of Streamers in Pulsed Corona and Dielectric Barrier Discharges, IEEE Transitions on plasma science, Vol.32, No. 1

[45] Kogelschatz, U.; Eliasson B. \& Hirth, M. (1987). Ozone generation from oxygen and air: Discharge physics and reaction mechanisms, Ozone: Science \& Engineering, Vol. 9, 367-377

[46] Eliasson, B.; Hirth, M. \& Kogelschatz, U. (1987). Ozone synthesis from oxygen in dielectric barrier discharges, J. Phys. D, Appl. Phys., Vol. 20, 1421-1437

[47] Viebahn-Haensler, R. (2002). The Use of Ozone in Medicine, Medicina Biologica, 4th edition

[48] Sugimoto, H. (1996). Basis and applications of ozone (in Japanese), Korin

[49] Tegeder, P.; Kendall, P.A.; Penno, M.; Mason N.J. \& Illenberger, E. (2001). Electron stimulated desorption of $\mathrm{O}$ - and $\mathrm{O}_{2}$ - from condensed ozone: Possible implications for the heterogeneous photochemistry of stratospheric $\mathrm{O}_{3}$, Physical Chemistry chemical Physics, Vol.3, 2625-2629

[50] Walker, I.C.; Gingell, J.M.; Mason N.J. \& Marston, G. (1996). Dissociative electron attachment (DEA) in ozone 0-10eV, Journal of Physics B: Atomic, Molecular and Optical Physics, Vol.29, 4749-4759

[51] Kuzumoto, M. (1998). Extremely narrow discharge gap ozone generator, Journal of Plasma and Fusion Research, Vol.74, No.10, 1144-1150

[52] Kanazawa, S. (2008). Dynamics and structure of ignition process in plasmas, Journal of Plasma Fusion Research, Vol.84, No.6, 348-355

[53] Kuzumoto, M. (1998). Extremely narrow discharge gap ozone generator, Journal of Plasma and Fusion Research, Vol. 74, No. 10, 1144-1150

[54] Pietsch, G. J; Gibalov, V. I. (1998). Dielectric barrier discharge and ozone synthesis, Pure E Appl. Chem., Vol. 70, No. 6, 1169-1174

[55] AHN, H. S.; Hayashi, N.; Ihara, S. \& Yamabe, C. (2003). Ozone generation characteristics by superimposed discharge in oxygen-fed ozonizer, Jpn. J. Appl. Phys., Vol. 42, Part 1, No. 10, 6578-6583 
[56] Kimura, T.; Hattori, Y. \& Oda, A. (2004). Ozone production efficiency of atmospheric dielectric barrier discharge of oxygen using time-modulated power supply, Japanese Journal of Applied Physics, Vol. 43. No. 11A, 7689-7692

[57] Golota, V. I.; Zvavada, L. M.; Kadolin, B. B.; Paschenko, I. A.; Pugach, S. G.; Taran, G. V. \& Yakovlev, A. V. (2004). Pulsed discharge for ozone synthesis, Proceedings of XV International Conference on Gas Discharge and their Applications, Toulouse, France

[58] Simek, M. \& Clupek, M. (2002). Efficiency of ozone production by pulsed positive corona discharge in synthetic air, Journal of Physics D; Applied Physics, Vol. 35, 11711175

[59] Takaki, K.; Hatanaka, Y.; Arima, K.; Mukaigawa, S. \& Fujikawara, T. (2009). Influence of electrode configuration on ozone synthesis and microdischarge property in dielectric barrier discharge reactor, Vacuum, 83, 128-132

[60] Fang, Z.; Qiu, Y.; Sun, Y.; Wang, H. \& Edmund, K. (2008). Experimental study on discharge characteristics and ozone generation of dielectric barrier discharge in a cylinder-cylinder reactor and a wire-cylinder reactor, Journal of Electrostatics, 66, 421-426

[61] Takayama, M.; Ebihara, K.; Stryczewska, H.; Ikegami, T.; Gyoutoku, Y.; Kubo, K. \& Tachibana, M. (2006). Ozone generation by dielectric barrier discharge for soil sterilization, Thin Solid Films, 506-507, 396-399

[62] Park, S.L.; Moon, J. D.; Lee, S. H. \& Shin, S. Y. (2006). Effective ozone generation utilizing a meshed-plate electrode in a dielectric-barrier discharge type ozone generator, Journal of Electrostatics, 64, 275-282

[63] Jung, J. S. \& Moon, J. D. (2008). Corona discharge and ozone generation charactristics of a wire-plate discharge system with glass-fiber layer, Journal of Electrostatics, 66, 335341

[64] Sung, Y. M. \& Sakoda, T. (2005). Optimum conditions for ozone formation in a micro dielectric barrier discharge, Surface \& Coatings Technology, 197, 148-153

[65] Yamamoto, M.; Ehara, Y.; Kishida, H. \& Itho, T. (1997). Ozone generation using threephase asymmetrical system, Proceedings of 6th Annual Conference on ozone Science and Technology in Japan, pp. 63-65

[66] Kitayama, J. \& Kuzumoto, M. (1997). Theoretical and experimental study on ozone generation characteristics of an oxygen-fed ozone generator in silent discharge, Journal of Physics. D: Applied Physics, 30, 2453-2461

[67] Kitayama, J. \& Kuzumoto, M. (1999). Analysis of ozone generation from air in silent discharge", Journal of Physics D: Applied Physics, 32, 3032-3040

[68] Stryczewska, H. D.; Ebihara, K.; Takayama, M.; Gyoutoku, Y. \& Tachibana, M. (2005). Non-thermal plasma-based technology for soil treatment, Plasma Processes and Polymers, 2, 238-245

[69] Toyofuku, M.; Ohtsu, Y. \& Fujita, H. (2004). High ozone generation with a highdielectric-constant material, Japanese Journal of Applied Physics, Vol. 43, No. 7A, 43684372

[70] Kuzumoto, M.; Tabata, Y. \& Shiono, S. (1997). Development of a very narrow discharge gap ozone generator -Generation of high concentration ozone up to $20 \mathrm{wt} \%$ for pulp bleaching-, Kami Pa Gikyoushi/Japan Tappi Journal, 51(2), 345-350 
[71] Zhang, Z.; Bai, X.; Bai, M.; Yang, B. \& Zhou, X. (2003). An ozone generator of miniaturization and modularization with the narrow discharge gap, Plasma Chemistry and Plasma Processing, 23(3), 559-568

[72] Itoh, H.; Teranishi, K. \& Shimomura, N. (2008). Ozone yield efficiency of piezoelectric transformer-based ozone generator, Proceedings of 18th Annual Conference on ozone Science and Technology in Japan, pp. 149-152

[73] Wang, D.; Namihira, T.; Katsuki S. \& Akiyama, H. (2010). Development of Higher Yield Ozonizer Based on Nano-Seconds Pulsed Discharge, Journal of Advanced Oxidation Technologies, Vol.13, No.1, 71-78

[74] Namihira, T.; Wang, D \& Akiyama, H. (2009). Pulsed power technology for pollution control, Physica Polonica A, Vol.115, No.6, 953-955

[75] Namihira, T.; Wang, D.; Matsumoto, T.; Okada, S. \& Akiyama, H. (2009). Introduction of nano-seconds pulsed discharge plasma and its applications (in Japanese), IEEJ Transactions on Fundamentals and Materials, Vol.129, No.1, 7-14 


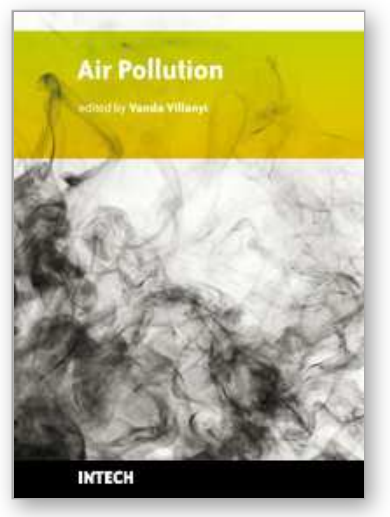

\author{
Air Pollution \\ Edited by Vanda Villanyi
}

ISBN 978-953-307-143-5

Hard cover, 370 pages

Publisher Sciyo

Published online 17, August, 2010

Published in print edition August, 2010

Although the climate of the Earth is continually changing from the very beginning, anthropogenic effects, the pollution of the air by combustion and industrial activities make it change so quickly that the adaptation is very difficult for all living organisms. Researcher's role is to make this adaptation easier, to prepare humankind to the new circumstances and challenges, to trace and predict the effects and, if possible, even decrease the harmfulness of these changes. In this book we provide an interdisciplinary collection of new studies and findings on the score of air pollution.

\title{
How to reference
}

In order to correctly reference this scholarly work, feel free to copy and paste the following:

Douyan Wang, Takao Namihira and Hidenori Akiyama (2010). Pulsed Discharge Plasma for Pollution Control, Air Pollution, Vanda Villanyi (Ed.), ISBN: 978-953-307-143-5, InTech, Available from:

http://www.intechopen.com/books/air-pollution/pulsed-discharge-plasma-for-pollution-control

\section{INTECH}

open science | open minds

\section{InTech Europe}

University Campus STeP Ri

Slavka Krautzeka 83/A

51000 Rijeka, Croatia

Phone: +385 (51) 770447

Fax: +385 (51) 686166

www.intechopen.com

\section{InTech China}

Unit 405, Office Block, Hotel Equatorial Shanghai

No.65, Yan An Road (West), Shanghai, 200040, China 中国上海市延安西路65号上海国际贵都大饭店办公楼405单元

Phone: +86-21-62489820

Fax: $+86-21-62489821$ 
(C) 2010 The Author(s). Licensee IntechOpen. This chapter is distributed under the terms of the Creative Commons Attribution-NonCommercialShareAlike-3.0 License, which permits use, distribution and reproduction for non-commercial purposes, provided the original is properly cited and derivative works building on this content are distributed under the same license. 